\title{
DESENVOLVIMENTO MARSUPIAL E PŌS-MARSUPIAL DE JANAIRA GRACILIS (CRUSTACEA, ISOPODA, ASELLOTA)
}

\author{
ANA MARIA SETUBAL PIRES*
}

Instituto Oceanogräfico da Universidade de São Paulo

\section{SYNOPSIS}

The development and growth of Janaira gracilis are described and discussed. The sampling was carried out once a month from January 1972 to January 1973 at the pier of Base Norte, Instituto Oceanogräfico USP, Ubatuba, State of São Paulo. Four distinct marsupial stages were disclosed in the development of Janaira gracilis as well as 9 distinct postmarsupial stages for the females and 10 for the males. Every postmarsupial instar can be distinguished by morphological features, such as first antennae articles, first and seventh pereopod, first and second pair of pleopods and the oostegites. During the course of development females undergo less morphological changes than males. Considering the final stages, in average males are larger than females. It is suggested that the decrease in growth of females may be related to the crescent energy demand for reproduction. Males reach sexual maturity before females.

\section{INTRODUÇÃO}

Há na literatura razoável soma de informações sobre a biologia dos Isopoda, e vários são os estudos referentes aos estádios de desenvolvimento das espécies (Sфmme, 1941; Forsman, 1944; Kjennerud, 1952; Naylor, 1955; Matsakis, 1956; Holdich, 1968; Hessler, 1970; Moreira, 1973). Sobre este assunto,

* Bolsista da Fundação de Amparo à Pesquisa do Estado de São Paulo (Proc.: Biológicas 71/1359). 
as investigações têm se tornado cada vez mais freqüentes, principalmente devido a falta de conhecimento das formas jovens.

Em relação aos Asellota marinhos são poucos os estudos abordando estádios de desenvolvimento, destacando-se entre eles os de Forsman (op. cit.), Bocquet (1953), Renault (1958) e Hessler (op. cit.).

Janaira gracilis Moreira \& Pires, 1975, pertence à subordem Asellota e ocorre em diferentes algas da região litoral do Estado de São Paulo. A espécie mostrou ser o Isopoda mais abundante da fauna vágil de Sargassum cymosum. Esta alga forma densos crescimentos em regiões abrigadas do 1itoral do Estado de São Paulo (Joly, 1964), notadamente na Enseada do Flamengo, litoral norte. 0 objetivo do presente trabalho é a enumeração e caracterização dos estádios marsupiais e pós-marsupiais de Janaira gracilìs, o estudo comparativo do desenvolvimento dos vários apêndices utilizados na descrição dos estádios, além da obtenção de informações sobre o crescimento da espécie.

\section{MATERIAL E MÉTODOS}

0 material foi coletado da fauna de Sargassum cymosum na Enseada do Flamengo, a $23^{\circ} 30^{\prime} \mathrm{S}$ e $45^{\circ} 07^{\prime} \mathrm{W}$, junto ao trapiche do Instituto Oceanogräfico da USP, Ubatuba, Estado de São Paulo (Fig. 1). A espécie revelou-se material excelente para o presente estudo, dado o grande número de animais encontrado em todas as fases de desenvolvimento, o que nos permitiu dispor de uma série completa e abundante dos estádios sucessivos.

O material biológico foi obtido mensalmente, de janeiro de 1972 a janeiro de 1973. Paralelamente, mediu-se a temperatura do ar e da água e coletou-se amostras d'água para a determinação da salinidade e do conteúdo de oxigênio dissolvido.

As coletas realizaram-se preferencialmente na marē baixa, mas com a alga sempre coberta pela água. Foram efetuadas coletas diurna e noturna para a investigação de possíveis diferenças qualitativas e quantitativas na composição da população nesses dois períodos. Como se constatou variações mínimas 
e não consistentes, as informações foram agrupadas mensalmente, num só conjunto de dados.

0 método de amostragem e tratamento do material biológico foi baseado em Dah1 (1948), Hagerman (1966), Dommasnes (1969) e Fish (1970), adaptado às nossas condições de trabalho, como abaixo descrito.

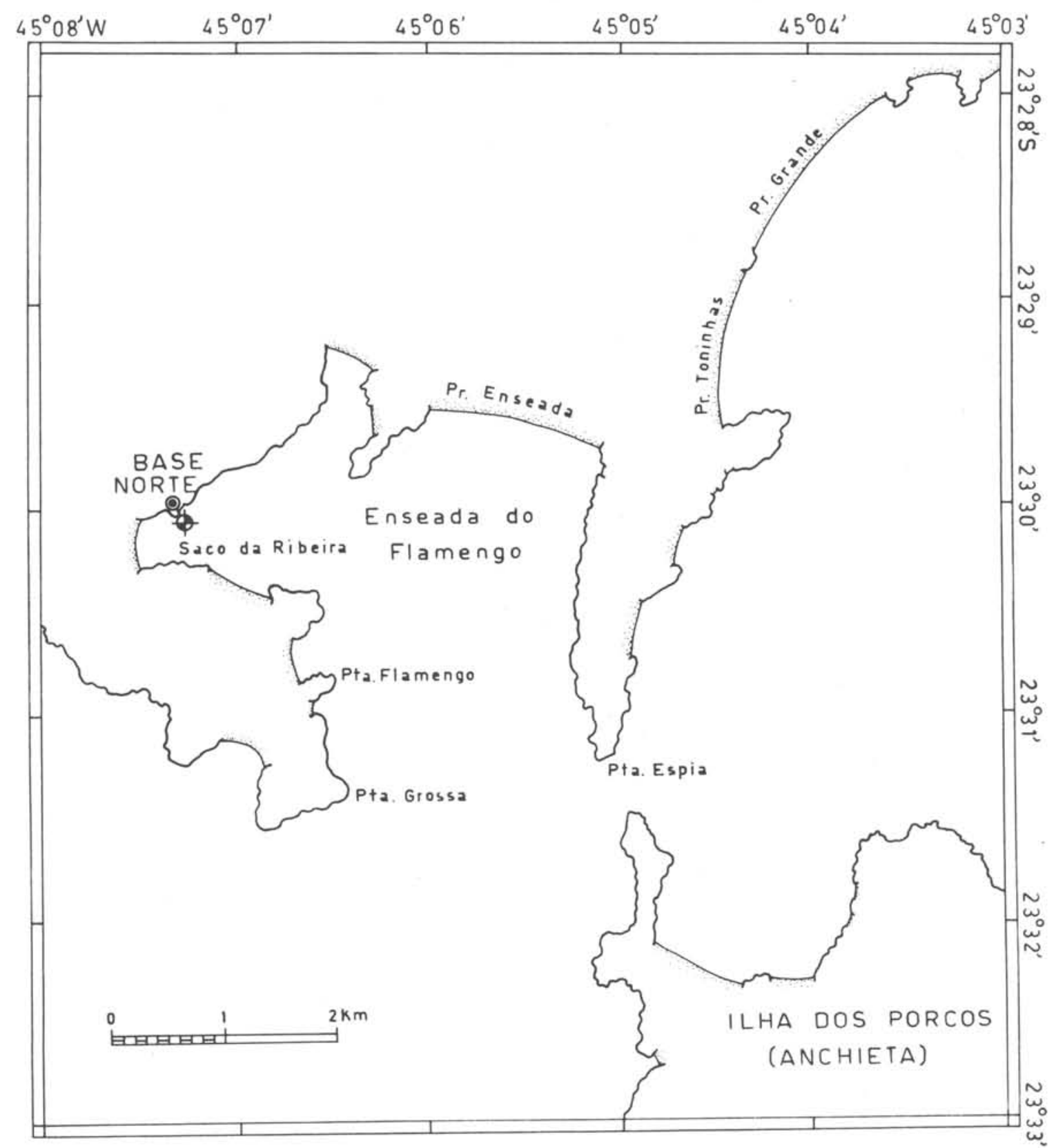

Fig. 1 - Localização da estação de coleta. 
0 comprimento total do animal foi tomado em vista dorsal, da margem ântero-mediana da cabeça ao ápice do pleotelson, sob microscópio estereoscópico e com auxílio de câmara clara. 0 corpo foi ligeiramente comprimido dorsoventralmente com a ponta de uma pinça e os jovens muito pequenos sofreram leve compressão com lamínula de vidro. A mensuração da imagem projetada efetuou-se com uma escala milimetrada. Os ovos foram medidos no seu diâmetro, como do modo descrito. Todas as leituras foram expressas em milímetro.

Cada amostra constou de aproximadamente $500 \mathrm{~g}$ de Sargassum, obtidas arrancando-se um tufo por vez e colocando-o rapidamente dentro de um saco plástico. No laboratório da Base toda a alga foi lavada, por agitação, em 4 baldes sucessivos contendo água ligeiramente formalizada, provocando-se com esse processo a saída da fauna vágil para os recipientes de lavagem. 0 conteúdo de cada balde foi então filtrado em rede de zooplâncton (malha de $295 \mu$ ) e o resíduo contendo a fauna depositada, conservado em álcool 70\%. A seguir os tufos jā lavados foram postos a secar sobre papel absorvente por determinado período de tempo $(01: 20 \mathrm{~h})$, após o que sofreram pesagem. Desta maneira obteve-se a fauna vágil e o peso ümido do Sargassum em cada estação de coleta.

A população de Janaira gracilis foi triada da fauna total, os espécimens contados e classificados em jovens, machos e fêmeas.

Dosou-se a salinidade segundo o método de Harvey (Harvey, 1955), e o oxigênio dissolvido pelo método de Winkler (Strickland \& Parsons, 1968). As temperaturas do ar e da água foram tomadas no local, logo no início de cada coleta.

\section{AMB I ENTE}

Durante o período amostrado, no momento das coletas, a temperatura do ar variou entre $18,5-30,5^{\circ} \mathrm{C}$. A temperatura mínima foi registrada em julho e outubro e a máxima em março. A temperatura da água variou entre $22,0-28,5^{\circ} \mathrm{C}$, estando a mínima localizada em julho e outubro e a máxima em março e janeiro de 1973. 
Os valores de salinidade estiveram compreendidos entre $31,2-35,4 \%$ e os do oxigênio dissolvido na ägua entre 3,75-5,00 $\mathrm{ml} / 1$ nas coletas diurnas e entre 3,24-4,48 $\mathrm{ml} / 1$ nas amostragens noturnas.

o local de coleta é de modo calmo e bastante abrigado do impacto das ondas de mar aberto (Fig. 1). Sargassum cymosum cresce fixo a substrato rochoso, sob a forma de tufos longos e densos, ocupando o limite inferior da zona das marēs.

\section{RESULTADOS}

0 desenvolvimento dos Isopoda, como o de todo crustáceo pertencente à superordem Peracarida, faz-se em duas etapas. A primeira, a marsupial, ocorre dentro do marsúpio e compreende ovos e embriões; a segunda, a pós-marsupial ou de vida livre, engloba os jovens e adultos.

Janaira gracilis apresenta 4 estádios de desenvolvimento marsupial, 9 estádios de desenvolvimento pós-marsupial para as fêmeas e 10 para os machos.

\section{DESENVOLVIMENTO MARSUPIAL}

ESTĀDIO A - Ovos de cor alaranjada, amarela ou às vezes verde brilhante; coloração uniforme dentro de um mesmo marsúpio. Inicialmente esféricos, tornam-se ovalados com o decorrer do desenvolvimento. Diâmetro médio de $150 \mu$.

Uma só membrana visível circundando todo o vitelo (Fig. 4); na periferia tem início a diferenciação dos apêndices. Há o aparecimento de uma fenda na superfície dorsal do ovo, que posteriormente atinge o centro do mesmo. E então possível distinguir-se a região da cabeça do restante do corpo (Fig. 5). No final do estádio a membrana, amarfanhada em material conservado em ālcool, rompe-se.

ESTĀDIO B - Embrião alongado, envolto pela primeira membrana embrionária e com típico formato de vírgula (Fig. 6). Comprimento médio de $200 \mu$. Distinção morfológica entre apêndices da cabeça e do pereon (Fig. 7). 
ESTẢDIO C - Apêndices cefálicos, do pereon e do pleon diferenciados, segmentados, mas não funcionais. Embrião envolto pela segunda membrana embrionária que cobre individualmente os apêndices (Fig. 8). Cerdas ausentes. Vitelo presente em pequena quantidade no interior do corpo. Comprimento médio de $330 \mu$.

ESTADIO D - Embrião totalmente livre, não mais circundado por membrana. Todos os apêndices formados (com exceção do pereópodo VII) e funcionais. Antena 1 com 4 artículos no flagelo e 1 esteto apical (Fig. 14); antena 2 com 7 artículos no flagelo. Pereonito VII muito menor que o VI; placas coxais visíveis nos pereonitos I-VI (Fig. 9). Embrião totalmente transparente, com olhos pigmentados, sem vitelo e com tubo digestivo visível. Comprimento médio de $480 \mu$.

0 desenvolvimento marsupial termina neste estādio e o animal está pronto para deixar o marsúpio. 0 estádio D corresponde ao primeiro de vida livre (pós-marsupia1).

Na fase marsupial ovos e embriões encontram-se numa mesma fase de desenvolvimento dentro de um mesmo marsúpio. Foram raros os casos contrārios, sendo que apenas $1 \%$ das fêmeas examinadas apresentaram ovos e embriões, ou embriões em duas etapas distintas. Neste caso as etapas de desenvolvimento foram sempre consecutivas e com predominância de uma delas.

\section{DESENVOLVIMENTO POS-MARSUPIAL}

Podem ser reconhecidas 3 fases distintas no desenvolvimento pós-marsupial dos Isopoda. Seguindo a nomenclatura adotada por Matsakis (1962) temos :

1. fase indiferenciada: o sexo não pode ser identificado externamente;

2. fase de imaturidade sexual: os sexos são reconhecíveis externamente, porém os animais são incapazes de se reproduzirem;

3. fase adulta: animais com capacidade de reprodução.

Uma fase pode incluir um ou vários estādios e o número deles vai depender da espécie e das condições ambientais em que ela vive. As principais ca- 
racterísticas utilizadas na definição dos estādios foram: número de artículos e de estetos no flagelo da antena 1, número de artículos da antena 2 (quando possíve1), morfologia do pereópodo I, diferenciação do pereópodo VII, comprimento do corpo e caracteres sexuais externos (desenvolvimento dos pleópodos 1 e 2 no macho e aparecimento de oostégitos na fêmea). Apresentamos, a seguir, a descrição morfológica dos animais em cada estádio de desenvolvimento.

ESTẢDIO 1 - Compreende os jovens recém-saídos do marsúpio materno. Corresponde à ūitima etapa marsupial.

A cabeça é relativamente grande quando comparada ao corpo. A relação encontrada entre comprimento da cabeça e comprimento total do corpo em um animal deste estádio é de $1: 3,7$, enquanto que em um macho do estádio 9 é de $1: 6,5$. Comprimento do corpo: $0,40-0,60 \mathrm{~mm}$.

ESTĀDIO 2 - Flagelo da antena 1 com 4 artículos e 1 esteto apical (Fig. 15); flagelo da antena 2 com 10 artículos. Pereonito VII maior que no estádio anterior, mas ainda menor e morfologicamente diferente do VI; não há esboço do sétimo par de pereópodos. Comprimento do corpo: 0,53-0,64 mm (Fig. -10).

ESTÁDIO 3 - Flagelo da antena 1 com 4 artículos e 1 esteto apical (Fig. 16); flagelo da antena 2 com 12-15 artículos. Aparecimento do pereópodo VII, dispondo-se transversalmente à região médio-ventral do pereonito VII, dobrados sobre si mesmos e voltados em direção ao pleotelson. Não são funcionais (Fig. 11). Pereonito VII maior que no estádio anterior, morfologicamente semelhante ao VI, porém menor que este (Fig. 12). Sexo indeterminado. Comprimento do corpo: $0,61-0,80 \mathrm{~mm}$.

ESTĀDIO 4 - Flagelo da antena 1 com 4 artículos e 1 esteto apical, o segundo artículo caracteristicamente muito alongado (Fig. 17); flagelo da antena 2 com 17-24 artículos. Pereópodo VII completamente desenvolvido e funcional; pereonito VII também totalmente desenvolvido (Fig. 13). Em grande parte dos animais o primeiro par de pleópodos se diferencia (Fig. 52) permitindo assim distinguir-se os machos. 
Outra característica importante do estādio 4, para os machos jovens, é o início da diferenciação do órgão copulador (formado por diferenciação do pleópodo 2). 0 endópodo forma o apêndice masculino, que aqui aparece de maneira incipiente: curto, rígido e com a parte distal arredondada (Fig. 59). Comprimento do corpo: 0,74-1,02 mm.

ESTĀDIO 5 - Flagelo da antena 1 com 5 artículos e 2 estetos, sendo um apical e um situado lateralmente no terceiro artículo (Fig. 18); flagelo da antena 2 com 25-34 artículos. Carpo do pereópodo I, nos machos, ligeiramente mais alargado que nas fêmeas (Figs 37 e 47). Pleópodo 1 alcançando o mesmo comprimento dos demais. Pleópodo 2 morfologicamente semelhante ao do estádio anterior, somente com o apêndice copulador mais alongado e não atingindo ainda o bordo do exópodo (Fig. 60). Comprimento do corpo: 0,90-1,17 mm.

A partir deste estādio há o acréscimo de 1 esteto lateral à antena 1 em cada etapa sucessiva do crescimento dos machos; para as fêmeas o mesmo acontece só até o estádio seguinte. 0 esteto apical permanece único.

ESTĀDIO 6 - Neste estádio ocorre a grande transformação do pleópodo 2 masculino, que vai caracterizar a pré-puberdade (ūitimo estādio da fase de imaturidade sexual).

Flagelo da antena 1, tanto em machos quanto em fêmeas, geralmente com 6 artículos e 3 estetos (Figs 19 e 29), mas pode ter tambēm, às vezes, 6 artículos e 2 estetos. Flagelo da antena 2 com 34-43 artículos.

Os jovens mostram dimorfismo sexual no pereópodo I. Esse apêndice tende a tornar-se distintamente subquelado nos machos, por alargamento do carpo, - qual também apresenta, na margem ventral, cerdas compostas pareadas e mais densamente distribuídas em relação ao estádio anterior (Fig. 36). Nas fêmeas, o pereópodo I é fracamente subquelado (Fig. 46). Esse dimorfismo fica cada vez mais acentuado à medida que progridem os estādios de crescimento.

0 örgão masculino assume a forma adulta. 0 apêndice masculino torna-se longo e afilado no ápice, atingindo a margem distal do pleópodo 2, que também apresenta poucas cerdas simples (Fig. 61). Comprimento do corpo: 1,15$1,60 \mathrm{~mm}$. 
ESTADIO 7 - MACHOS - A grande maioria possui 7 artículos e 4 estetos no flagelo da antena 1 (Fig. 20), mas, às vezes, pode-se encontrar flagelos com 8 artículos e 4 estetos; flagelo da antena 2 com 46-64 artículos. Comprimento do corpo: 1,53-1,93 mm.

A partir deste estádio o pereópodo I e os pleópodos 1-2 não sofrem mais transformações notāveis. Nos 3 estádios seguintes há somente crescimento e aumento na ornamentação desses apêndices.

FÊMEAS - Flagelo da antena 1 com 6 artículos e 3 estetos (Fig. 30); flagelo da antena 2 com mais de 44 segmentos. Diferenciação dos oostégitos, na parte basal dos 4 primeiros pares de pereópodos, que aparecem como pequeninas lâminas somente visíveis sob cuidadoso exame ao microscópio. Na metade anterior do pereon de algumas fêmeas é possíve1 notar-se, por transparência da parede do corpo e em vista dorsal, poucos e pequenos ovos dentro dos ovários. Comprimento do corpo: 1,50-2,00 mm.

ESTĀDIO 8 - MACHOS - Antena 1 com 8 artículos e 5 estetos no flagelo (Fig. 21); flagelo da antena 2 com cerca de 76 artículos. Comprimento do corpo: $1,74-2,26 \mathrm{~mm}$.

FÊMEAS - Flagelo da antena 1 com 6 ou 7 artículos e 3 ou 4 estetos (Fig. 31); flagelo da antena 2 com mais de 62 artículos, estando na maioria das vezes partido. Oostégitos maiores que no estádio anterior (cerca de $2 / 3$ do basipodito) apresentando-se como lamelas rígidas, facilmente visíveis sob microscópio estereoscópico. Pode-se observar ovos nos ovários de muitas fêmeas colocadas em vista dorsal. Ovários mais alargados e ovos maiores em relação ao estádio 7. Comprimento do corpo: 1,80-2,80 mm.

A cópula ocorre durante a muda para o próximo estádio.

ESTÁDIO 9 - MACHOS - Flagelo da antena 1 com 9 artículos e 6 estetos (Fig. 22); flagelo da antena 2 com número superior a 84 segmentos. Comprimento do corpo: $1,90-3,00 \mathrm{~mm}$.

FÊMEAS - Antena 1 com 6 ou 7 artículos no flagelo e 3 ou 4 estetos, como no estádio anterior (Fig. 32). Todas as antenas 2, examinadas, mostraram-se danificadas. Os oostégitos formam, agora, o marsúpio que abriga 
em seu interior ovos ou embriões ou, então, aparece vazio. Comprimento do corpo: $1,80-3,00 \mathrm{~mm}$.

Após este estádio, algumas fêmeas podem sofrer nova muda, perder o marsúpio flácido e adquirir oostégitos, ficando semelhante às fêmeas do estádio 8. Estes animais teriam, então, 10 estádios de desenvolvimento pós-marsupial.

ESTĀDIO 10 - E bem caracterizado nos machos. Flagelo da antena 1 com 10 artículos e 7 estetos (Fig. 23); flagelo da antena 2 com cerca de 100 artículos. Carpo do pereópodo I, bastante alargado e ornamentado, conferindo ao apêndice uma aparência fortemente subquelada (Fig. 42). Comprimento do corpo: $2,40-2,70 \mathrm{~mm}$.

\section{DESENVOLVTMENTO DOS VĀRIOS APÊNDICES ESTUDADOS}

ANTENA 1 - Hā um crescimento diferencial da antena 1 em machos e fêmeas. Comparando-se o desenvolvimento desse apêndice em ambos os sexos (Figs 1432) pode-se ver claramente que até o estádio 6 o padrão é o mesmo tanto para machos quanto para fêmeas. No entanto, a partir do estádio 7 , o crescimento da antena 1 dos machos supera o das fêmeas e continua a ser feito através do acréscimo de 1 artículo e de um esteto lateral a cada muda sucessiva. Nas fêmeas, no estádio 7, a antena 1 apresenta o mesmo número de artículos e de estetos em relação à etapa anterior, enquanto que nos estádios 8 e 9 , pode ter tanto 6 como 7 artículos e 3 ou 4 estetos, embora a maior parte da população estudada possua 7 artículos e 3 estetos.

\section{OBSERVAÇÕES :}

Em muitos indivỉduos hā uma diferença quanto ao nümero de artículos no flagelo direito e esquerdo. Na maioria dos casos examinados, o lado que apresenta um segmento a menos possui o segundo artículo do flagelo antenular muito 1ongo. Os animais portadores desta característica são incluídos no estádio correspondente ao lado que possui maior número de artículos no flagelo.

Há casos, também, em que ambos os lados mostram o segundo artículo muito longo, como se não houvesse sofrido divisão; è o que acontece, por exemplo, 
com muitas fêmeas do estádio 8. Consultando-se a Tabela I pode-se ver que $33,33 \%$ das fêmeas examinadas possuem 6 artículos como no estádio 7, porém têm todas as características do estādio 8 e a ele pertencem. Estes casos não são considerados anormais e indicam somente uma falta de divisão no artículo jā crescido e alongado após uma muda.

Uma outra observação feita na antena 1 refere-se à variação no número de estetos de um lado em relação ao outro. Quando essa diferença é de 1 só esteto e o número de artículos é o mesmo nas antenas direita e esquerda, provavelmente é porque houve perda de 1 esteto do lado em que há menor número deles. Neste caso, o animal é considerado pertencente ao estádio que corresponde ao maior número de estetos.

Se os casos descritos acima são considerados normais, temos, por outro lado, antenas 1 que fogem do padrão observado, apresentando-se com um número de artículos bem maior em um dos lados do animal e não havendo relacionamento com o número de estetos. Por exemplo, um animal com 7 artículos e 6 estetos no flagelo direito e 10 artículos e 7 estetos no esquerdo. Ocorrências como esta são raras dentro da população e não foram consideradas na determinação dos estádios pós-marsupiais.

TABELA I - Variação do nūmero de artículos e de estetos na antena l de fêmeas nos dois ültimos estādios pós-marsupiais

\begin{tabular}{|c|c|c|c|c|}
\hline ESTĀDIO & $\begin{array}{l}\text { ARTICULOS } \\
\text { (n?) }\end{array}$ & $\begin{array}{l}\text { ESTETOS } \\
\text { (n?) }\end{array}$ & $\mathrm{N}$ & $\%$ \\
\hline 8 & $6+$ & 3 & 13 & 33,33 \\
\hline 8 & 7 & 3 & 21 & 53,84 \\
\hline 8 & 7 & . 4 & 5 & 12,82 \\
\hline 9 & $6+$ & 3 & 14 & 20,28 \\
\hline 9 & 7 & 3 & 43 & 62,31 \\
\hline 9 & 7 & 4 & 12 & 17,39 \\
\hline
\end{tabular}


ANTENA 2 - A variação do número de artículos no flagelo é grande dentro de cada estádio e parece não obedecer a um padrão definido. Por exemplo, tem-se 34-43 artículos no estádio 6 e 44-64 no estādio seguinte. A antena 2 é 1onga e delicada, sendo freqüentemente encontrada danificada, principalmente nos estádios finais. Assim sendo, só um pequeno número de antenas puderam ser examinadas, o que impossibilitou um estudo detalhado do seu desenvolvimento. Os dados obtidos seguem apenas como complementação na descrição morfológica dos estádios.

PEREб́ODO I - 0 pereópodo I é o único apêndice locomotor que apresenta marcante dimorfismo sexual, sendo robusto e subquelado nos machos e fracamente subquelado nas fêmeas. 0 alargamento do carpo do pereópodo é o responsáve1 pela subquelação do apêndice e constitui carāter sexual secundário. Daí a importância em acompanhar seu desenvolvimento. Comparando-se a série de pereópodos masculinos (Figs 33-42), notamos que o alargamento do carpo iniciase no estádio 5, tornando-se evidente no 6 . E também neste estádio que a margem ventral desse artículo fica ornamentada com densa fileira de cerdas e assume a característica dos adultos. A forma adulta parece ser atingida no estádio 7, pois a partir dele, só há aumento de tamanho e ornamentação. observando-se a série de pereópodos femininos (Figs 43-51), vê-se que o apêndice conserva, durante o desenvolvimento, uma forma juvenil. As mudanças que ocorrem são principalmente quanto ao tamanho e ornamentação.

PLEбுODO 1 (masculino) - Chama a atenção, durante seu desenvolvimento, o alargamento que o apêndice sofre na parte basal, adquirindo com isto uma forma cada vez mais triangular, além de apresentar crescimento visível (Figs 52-58). A cada muda, a partir do estādio 4 e até o estádio 7 , há aumento de uma cerda simples na margem interna mediana e apical do pleópodo, começando com duas e chegando a cinco. Do estádio 8 em diante, há alteração desse padrão de crescimento, quando, então, aparecem sete cerdas e nos dois estádios seguintes, oito. A relação entre a porção basal e apical do apêndice vai gradativamente modificando-se. No estádio 8 a parte apical é aproximadamente duas vezes menor que o maior comprimento da basal (Fig. 56).

PLEరPODO 2 (masculino) - Este apêndice sofre grandes transformações no seu desenvolvimento. Aparece no estádio 4, com o exópodo rígido e reniforme, 
sendo o endópodo curto e robusto. No decorrer do desenvolvimento o exópodo vai se tornando mais delgado, havendo o aparecimento de cerdas delicadas na porção apical da lâmina, a partir do estádio 6 . 0 número de cerdas vai aumentando com os estádios (Figs 61-65). O endópodo, transformado em órgão copulador, tende a se alongar, estando no estádio 7 com a forma característica do adulto. A grande transformação do apêndice ocorre ao passar do estádio 5 (jovem) para o 6 (pré-adulto).

\section{CRESCIMENTO}

0 crescimento de Janaira gracilis foi obtido através do estudo da variação de comprimento dos animais em cada estádio do desenvolvimento pósmarsupial. Os resultados são apresentados na Tabela II e Figura 2. Utilizando-se da média de comprimento por estádio, construiu-se a curva de crescimento para machos e fêmeas, separadamente (Fig. 3). 0 que se observa, pri-
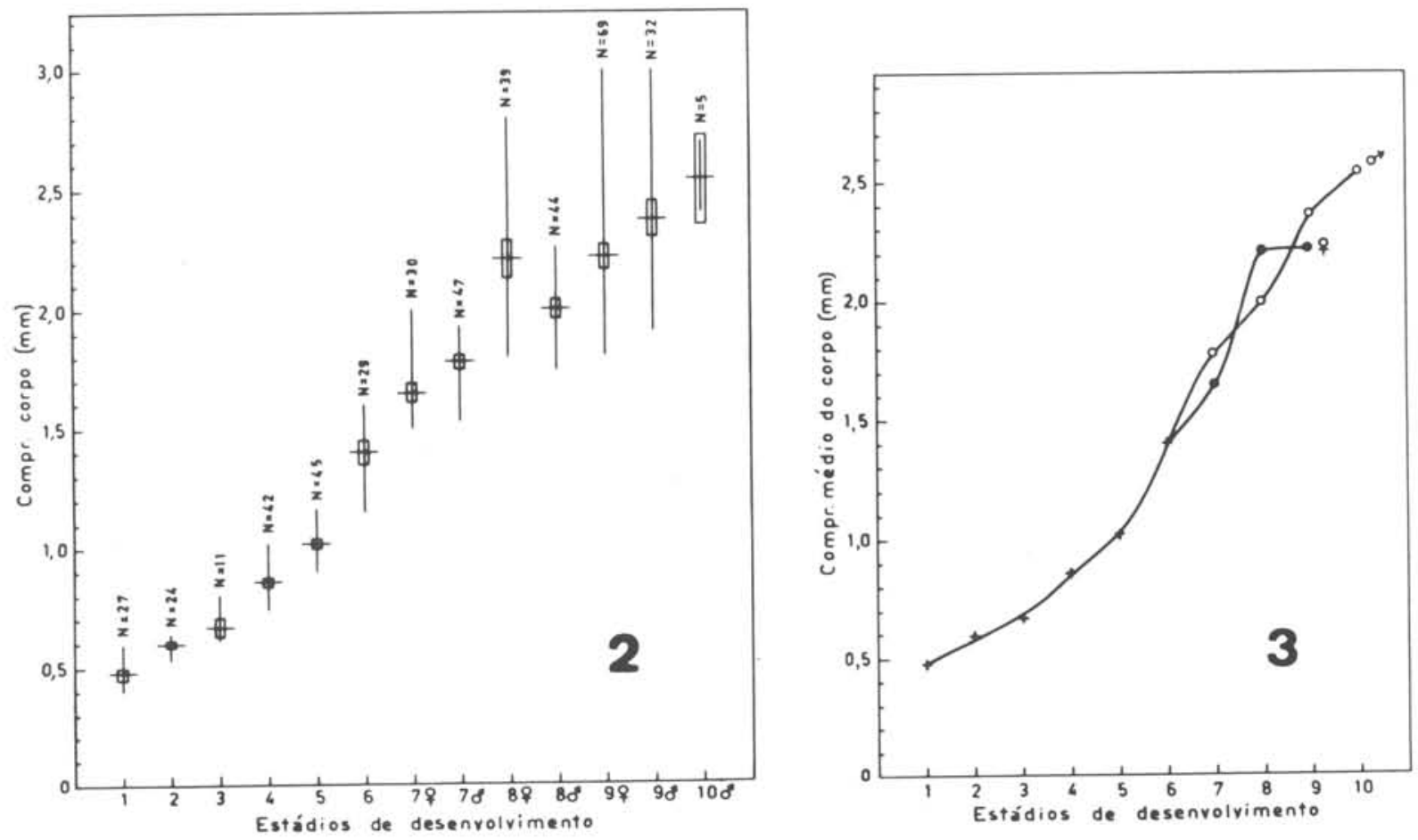

Fig. 2 - Variação do comprimento do corpo nos estädios de desenvolvimento pós-marsupial. A linha vertical representa a amplitude da amostra; na extremidade superior segue o nümero de observações; a linha horizontal indica a média e o retângulo o intervalo da média, ao nível de $5 \%$.

Fig. 3 - Curva de crescimento pós-marsupial para macho e fêmea de Janaira gracilis. 
meiramente, são as médias de comprimento bem definidas para cada estádio (com exceção dos estádios 8 e 9 das fêmeas, que serão discutidos mais adiante); hā uma certa sobreposição do limite máximo de um grupo em relação ao seguinte. A partir do estádio 7 os machos apresentam crescimento médio superior ao das fêmeas (exceto no estádio 8).

Os machos do ūltimo estádio são maiores, em média, do que as fêmeas no seu estādio final. Comprimento máximo atingido pelos machos: 3,00 mm. Comprimento máximo atingido pelas fêmeas: $3,30 \mathrm{~mm}$.

A variação de comprimento é muito útil para a caracterização dos estádios embora, sozinha, não sirva para defini-1os.

TABELA II - Comprimento mëdio dos animais por estädio pös-marsupial

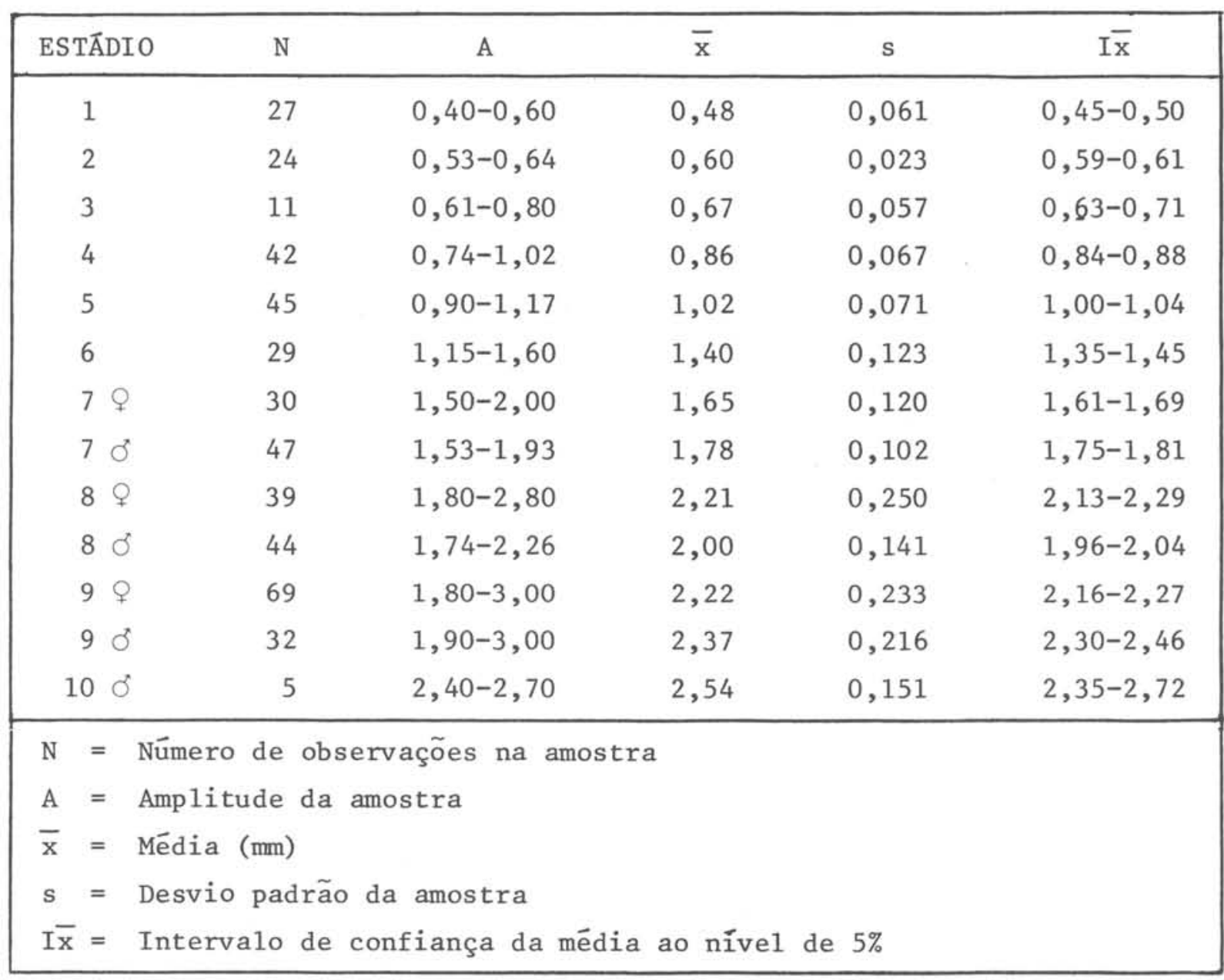




\section{DISCUSSÃO}

A seqüência de estádios marsupiais de Janaira gracilis coincide com o encontrado para outros Isopoda (Sфmme, 1941; Kjennerud, 1952; Holdich, 1968; Jones \& Naylor, 1971; Moreira, 1973). Por outro lado, o número de membranas envolvendo os ovos de Janaira gracilis concorda com o verificado por Kjennerud (op. cit.), Naylor (op. cit.), mas difere dos resultados apresentados por Holdich (op. cit.) e Sфmme (op. cit.).

Em Janaira gracilis, $99 \%$ das fêmeas possuem embriões no mesmo estādio de desenvolvimento. Esta uniformidade no desenvolvimento embrionário é também relatada nos trabalhos de Kjennerud (1952), Naylor (1955), Jones \& Naylor (1971), Moreira (1973), Jones (1974) e constitui regra geral entre os Crustacea (Green, 1965). Em Dynamene bidentata, porém, cerca de $25 \%$ das fêmeas possuem embriões em fases diferentes de desenvolvimento (Holdich, 1968) e em Idotea viridis, Howes (1939) observou que um mesmo marsúpio podia abrigar embriões totalmente desenvolvidos ao lado de outros em fases iniciais de desenvolvimento. 0 fato de em Janaira gracilis haver uma uniformidade no desenvolvimento marsupial sugere desova total num período reprodutivo e divisão sincrônica dos ovos.

0 número de estádios pós-marsupiais varia de uma espécie para outra e depende das condições ambientais em que vive o animal (Matsakis, 1956). Bocquet (1953) estudando o desenvolvimento pós-marsupial em Asellota, encontrou 6 estādios para as fêmeas de Jaera albifrons. Wolff (1962) achou para algumas espécies batiais e abissais de Asellota 6-7 estádios para as fêmeas e 6 para os machos. Hessler (1970) observou 10-12 estádios para as fêmeas e 7 para os machos de Eugerda tetarda (Asellota). Em outras subordens temos tambēm variação do número de estādios (Kjennerud, 1952; Matsakis, 1956; Holdich, 1968; Moreira, 1973; Talin, 1970). O nümero de estádios pós-marsupiais encontrado para Janaira gracilis está, portanto, dentro do observado entre os Isopoda.

Os resultados obtidos vieram confirmar que o número de artículos e o número de estetos no flagelo da antena 1 são ótimos indicadores do estádio de desenvolvimento em que se encontra o animal, à semelhança do observado para Jaera albifrons (Forsman, 1944), Mancasellus macroums (Markus, 1930), Ligia 
italica (Matsakis, 1955), Idotea neglecta (Kjennerud, 1952) e Dynamene bidentata (Holdich, 1968). Entretanto, estes mesmos caracteres não serviram para identificar todos os estádios de Idotea emarginata, pois Naylor (1955), utilizando-os, conseguiu separar apenas os três primeiros estádios. Em Janaira gracilis o flagelo antenular não apresenta acréscimo de artículos ou de estetos nos quatro primeiros estádios, estando a caracterização destes baseada principalmente no aparecimento e desenvolvimento do pereópodo VII.

Outro caráter freqüentemente empregado pelos pesquisadores è a variação do número de artículos no flagelo da antena 2 (Markus, 1930; Daguerre de Hureaux, 1959). Em Janaira gracilis essa característica não pôde ser utilizada com sucesso devido a escassez de indivíduos com antena 2 íntegra. Por ser o flagelo muito longo e delicado (chega a ter 100 artículos no macho adu1to) parte-se com extrema facilidade.

As transformações que ocorrem durante o desenvolvimento de Janaira gracilis são muito mais evidentes nos machos do que nas fêmeas. Nos machos aparecem modificações significantes no primeiro pereópodo, primeiro e segundo pleópodos e desde o estádio 4 podem ser facilmente identificados através do aparecimento do apêndice masculino. As fêmeas só são seguramente determinadas, morfologicamente, a partir do estádio 6. Os machos também são os primeiros a se diferenciar em muitas outras espécies (Kjennerud, 1952; Holdich, 1968; Moreira, 1973).

Como foi visto, os pleópodos 1 e 2 aparecem concomitantemente. 0 mesmo foi encontrado por Bocquet (1953) para Jaera albifrons, enquanto que difere do verificado por Wolff (1962) para alguns Asellota de profundidade. Wolff observou que um traço em comum para as 6 espécies que estudou era o aparecimento do pleópodo 1 antes do desenvolvimento do pleópodo 2 .

0 crescimento dos vários apêndices nos machos de Janaira gracilis mostra claramente em que ponto de seu desenvolvimento há a passagem da fase juveni1 para a de pré-puberdade. E quando ocorre a muda do estádio 5 para o 6 . Seguindo-se a nomenclatura adotada por Bocquet (1953), o estádio 5 corresponde ao que chamou de "avant pré-mâles", isto é, indivíduos preparando-se para a muda de pré-puberdade. 0 estádio 6, correspondente aos "prē-mâles", è a etapa de pré-puberdade. Segundo Bocquet (op. cit.), essa fase abrange um só estádio. Em Janaira gracilìs, a partir do estādio 7 não há mais modificações 
morfolögicas significativas nos vários apêndices analisados e o mesmo padrão observado nesse estádio è conservado nos subseqüentes, só havendo crescimento. A muda de puberdade deve ocorrer do estādio 6 para o 7, quando então, os machos são adultos. A pré-puberdade duraria um estádio, concordando com o encontrado por Bocquet.

Uma vez que as fêmeas conservam uma forma juvenil por grande parte de seu desenvolvimento (fato também observado por Hessler, 1970), é difícil de se precisar em que ponto ocorre a muda de pré-puberdade. Porēm, ao contrário do que acontece com os machos, nas fêmeas é fácil e segura a determinação da muda de puberdade. Esta ocorre do estádio 8 para o 9, quando se dā tambēm a copulação. Resumindo, esquematicamente, as fases de desenvolvimento pós-marsupial de Janaira gracilis, teríamos:

1. fase juvenil: compreendendo os estädios de 1 a 5 (animais indiferenciados e imaturos).

2. fase de pré-puberdade: atingida pelos machos no estádio 6 , e nas fềmeas é de difícil precisão. Os animais são imaturos.

3. fase de puberdade ou adulta: alcançada pelos machos no estádio 7, podendo se estender até o estádio 10; nas fêmeas abrange o estádio 9 e talvez o 10 .

Deve haver um menor crescimento das fêmeas na passagem do estádio 8 para - 9, em relação às mudas anteriores. Esta suposição é baseada no estudo do desenvolvimento da antena 1 e do pereópodo I. Embora haja muda para o estádio seguinte, pode não haver crescimento correspondente ou por ele ser muito pequeno. Este fato poderia ser causado por um desvio, para a reprodução, de grande parte das reservas da fêmea, que de outro modo seriam empregadas para fins de crescimento (Hessler, 1970; Carefoot, 1973).

$\mathrm{Na}$ análise da curva de crescimento de Janaira gracilis nota-se também o grande salto que ocorre na média de comprimento entre fêmeas dos estádios 7 e 8 (Tabela II). Os exemplares do estádio 7 constituem também um grupo bem mais homogêneo quanto ao comprimento, do que aqueles dos estádios 8 e 9 . Nestes dois últimos, deveremos ter fêmeas menores, em primeira gestação, ao lado de exemplares um pouco maiores, numa segunda reprodução. Isto explicaria o mesmo valor da média de comprimento e a grande variação de tamanho encontrada nos estádios 8 e 9, bem como o alto valor da média do estádio 8 em relação ao anterior. 


\section{CONCLUSÕES}

1. O desenvolvimento de Janaira gracilis faz-se através de 4 estádios marsupiais, 9 estádios pós-marsupiais para fêmeas e 10 para machos.

2. Os ovos ou embriões de um determinado marsúpio estão, em $99 \%$ dos casos, numa mesma fase de desenvolvimento.

3. Os machos são os primeiros a se diferenciarem morfologicamente (estádio 4) enquanto que as fêmeas só o fazem no estádio 5.

4. Os machos parecem atingir a maturidade sexual no estádio 7 , precocemente às fêmeas, que só o fazem no estádio 8 .

5. De um modo gera1, a partir do estádio 7, o crescimento dos machos supera o das fêmeas. Em média, os machos do último estádio são maiores do que as fêmeas em etapa final de crescimento. 0 comprimento do corpo, por si sō, não define um estádio, mas contribui para sua caracterização.

6. 0 crescimento das fêmeas na passagem para o último estádio (muda de maturação sexual) é menor do que o observado nas mudas precedentes. A grande variação de comprimento encontrada nos dois estádios finais deve-se, provavelmente, ao fato de em ambos existirem animais em primeira e segunda gestação.

\section{RESUMO}

No presente estudo são descritos os estádios de desenvolvimento de Janaira gracilis e discutidos vários aspectos de seu crescimento.

Coletou-se o material mensalmente, de janeiro de 1972 a janeiro de 1973, junto ao trapiche da Base Norte do Instituto Oceanográfico da Universidade de São Paulo, Ubatuba, Estado de São Paulo.

Janaira gracilis apresenta 4 estádios de desenvolvimento marsupial, 9 de desenvolvimento pós-marsupial para as fêmeas, e 10 para os machos. Os estádios pós-marsupiais podem ser bem determinados através do número de artículos do flagelo da antena 1, pereópodo I e VII, pleópodos 1 e 2 masculino e desenvolvimento de oostégitos na fêmea. 
As transformações decorrentes do desenvolvimento pós-marsupial são mais marcantes nos machos, pois as fêmeas conservam uma morfologia juvenil e uniforme durante toda a sua vida. 0 crescimento médio dos machos suplanta o das fêmeas a partir do estádio 7. Nestas, a diminuição de crescimento observada deve-se, provavelmente, à utilização crescente de energia disponível, para fins reprodutivos. Os machos alcançam a maturidade sexual precocemente às fêmeas.

\section{AGRADECIMENTOS}

Agradeço ao Prof. Dr. Plínio Soares Moreira pela orientação dada ao presente trabalho; ao Instituto Oceanográfico da Universidade de São Paulo pelo uso da Base Norte e pelas facilidades obtidas no decorrer desta pesquisa. Sou também grata à Srta. Leko Kanno por cobrir os desenhos a nanquim.

\section{BIBLIOGRAFIA}

BOCQUET, C. 1953. Recherches sur le polymorphisme nature1 des Jaera marina (Fabr.) (Isopodes Ase1lotes). Archs Zool. exp. gén., 90: 187-450.

CAREFOOT, T. H. 1973. Studies on the growth, reproduction, and life cycle of the supralittoral isopod Ligia pallasii. Mar. Biol., $18(4): 302-311$.

DAGUERRE DE HUREAUX, N. P. 1959. Contribution à l'étude du développement post-embryonnaire de Sphaeroma serratum (Fabricius) (Crustacé Isopode). Bu11. Soc. Sci. nat. phys. Maroc, 39(3-4): 167-174.

DAHL, E. 1948. On the smaller Arthropoda of marine algae, especially in the polyhaline waters off the Swedish west coast. Unders. Oresund, 35:1-193.

DOMMASNES, A. 1969. On the fauna of Corallina officinalis L. in western Norway. Sarsia, 38:71-86.

FISH, S. 1970. The biology of Eurydice pulchra (Crustacea: Isopoda). J. mar. biol. Ass. U. K., 50:753-768. 
Bolm Inst. oceanogr., S Paulo, 26, 1977

FORSMAN, B. 1944. Beobachtungen uber Jaera albifrons Leach an der schwedischen Westkuste. Ark. Zoo1., 35A(11):1-33.

GREEN, J. 1965. Chemical embriology of the Crustacea. Biol. Rev., $40(4): 580-600$.

HAGERMAN, L. $\quad$ 1966. The macro- and microfauna associated with Fucus serratus L., with some ecological remarks. Ophelia, 3:1-43.

HARVEY, H. W. 1955. The chemistry and fertility of sea waters. London, Cambridge University Press, viii + 224 p.

HESSLER, R. R. $\quad 1970 . \quad$ The Desmosomatidae (Isopoda, Asellota) of Gay Head-Bermuda Transect. Bul1. Scripps Instn Oceanogr., 15:1-185.

HOLDICH, D. M. 1968. Reproduction, growth and bionomics of Dynomene bidentata (Crustacea, Isopoda). J. Zool., 156:137-153.

HOWES, N. H. 1939. Observations on the biology and post-embryonic development of Idotea viridis (Slabber) (Isopoda, Valvifera) from New England Creek, South-east Essex. J. mar. biol. Ass. U. K., 23:279-310.

JOLY, A. B. 1964. Flora marinha do 1itoral norte do Estado de São Paulo e regiões circunvizinhas. Bolm Fac. Filos. Ciênc. Univ. S Paulo, Bot., (21):6-393 + 59 pranchas +4 mapas.

JONES, M. B. 1974 . Breeding biology and seasonal population changes of Jaera nordmanni nordica Lemercier (Isopoda, Asellota). J. mar. biol. Ass. U. K., 54:727-736.

\& NAYLOR, E. 1971. Breeding and bionomics of the British members of the Jaera albifrons group of species (Isopoda: Asellota). J. Zool., 165(2):183-199.

KJENNERUD, J. 1952. Ecological observations on Idotea neglecta G. 0. Sars. Univ. Bergen Arb. naturvid. rekke, (7):1-47.

MARKUS, H. C. 1930. Studies on the morphology and life history of the isopod Mancasellus macroums. Trans. Am. microsc. Soc., 49(3):220237.

MATSAKIS, J. 1955. Développement postembryonnaire chez Ligia itaZica. Vie Milieu, 6(1):113-119.

1956. Développement postembryonnaire d'Idotea viridis (S1abber) provenant de 1'étang de Leucate. Vieu Milieu, 7(2):287-300.

1962. Contribucion à l'étude du développement postembryonnaire et de 1a forme chez quelques crustacés isopodes. Bull. biol. Fr. Belg., 96:531-691. 
MOREIRA, P. S. 1973. Biologia de Serolis completa (Crustacea, Isopoda, Flabellifera). I. Estádios de desenvolvimento. Bolm Inst. oceanogr., S Paulo, 22:93-108.

\& PIRES, A. M. S. Janaira gracilis, a new genus and species of janirid isopod (Crustacea, Peracarida) from Brazil. Crustaceana (no prelo).

NAYLOR, E. 1955. The life cycle of the isopod Idotea emarginata (Fabricius). J. Anim. Eco1., 24(2):270-281.

RENAULT, 0. 1958. Note sur la morphologie et le développement de Jaera nordmanni (Rathke) (Isopode Asellote). Archs Zool. exp. gën., notes et rev., 96:63-70.

SøMME, 0. M. 1941. A study of the life history of the gribble Limnoria Zignomm (Rathke) in Norway. Nytt Mag. Naturvid., 81:145-205.

STRICKLAND, J. D. H. \& PARSONS, T. R. 1968. A practical handbook of seawater analysis. Bull. Fish. Res. Bd Can., (167):1-311.

TALIN, J. 1970. Sur le cycle biologique de Sphaeroma hookeri Leach (Isopode flabellifère) dans les eaux de la Durançole (b. du Rh.). Hidrobiologia, 36(2):295-303.

WOLFF, T. 1962. The systematics and biology of bathyal and abyssal Isopoda Asellota. Galathea Rep., 6:1-320, p1s 1-19. 


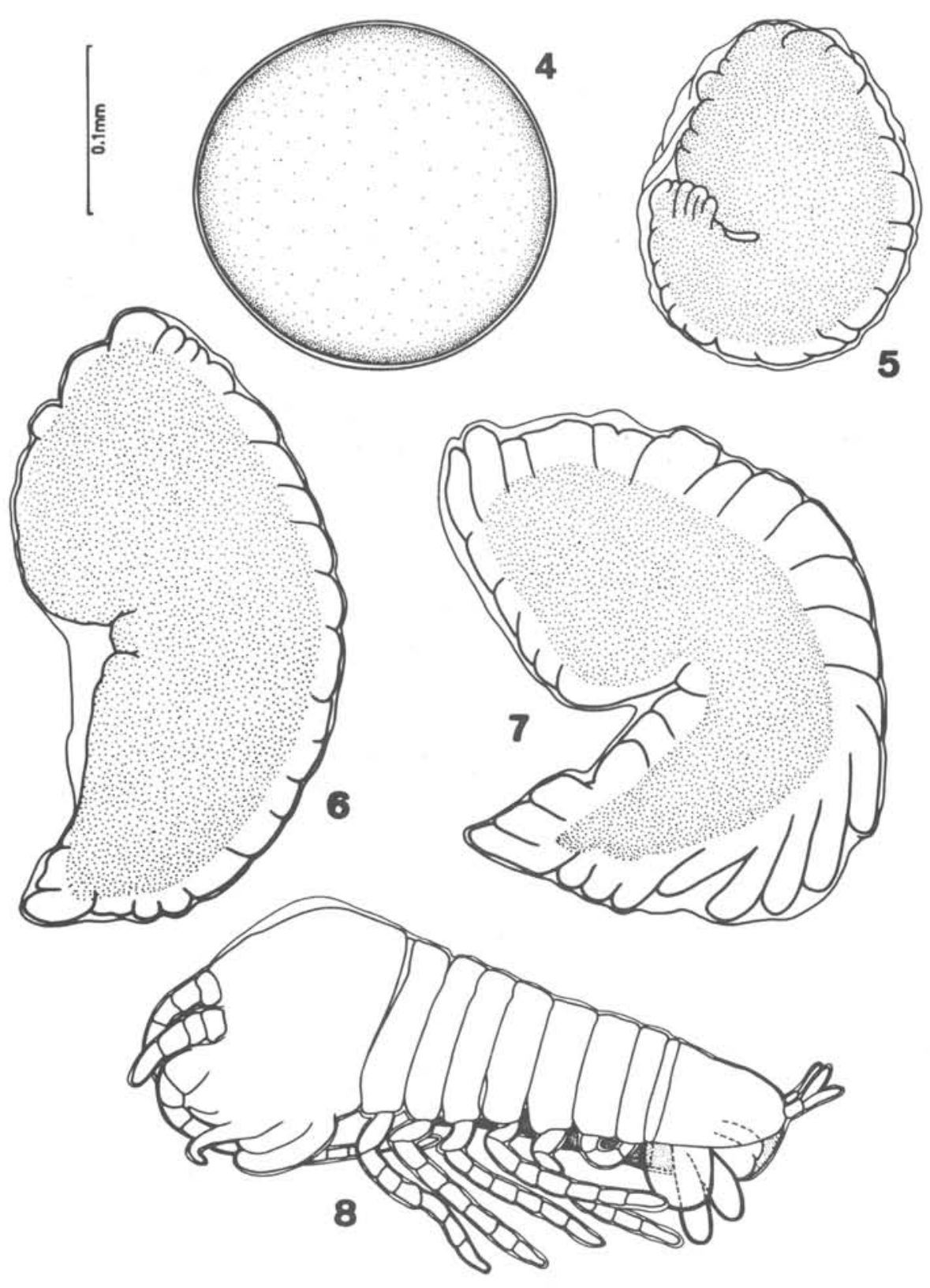

Fig. 4 - Estädio marsupial A, início.

Fìg. 5 - Estädio marsupial A, final.

Fig. 6 - Estädio marsupial B, início.

Fig. 7 - Estädio marsupial B, final.

Fig. 8 - Estädio marsupial C. Embrião em vista lateral. 


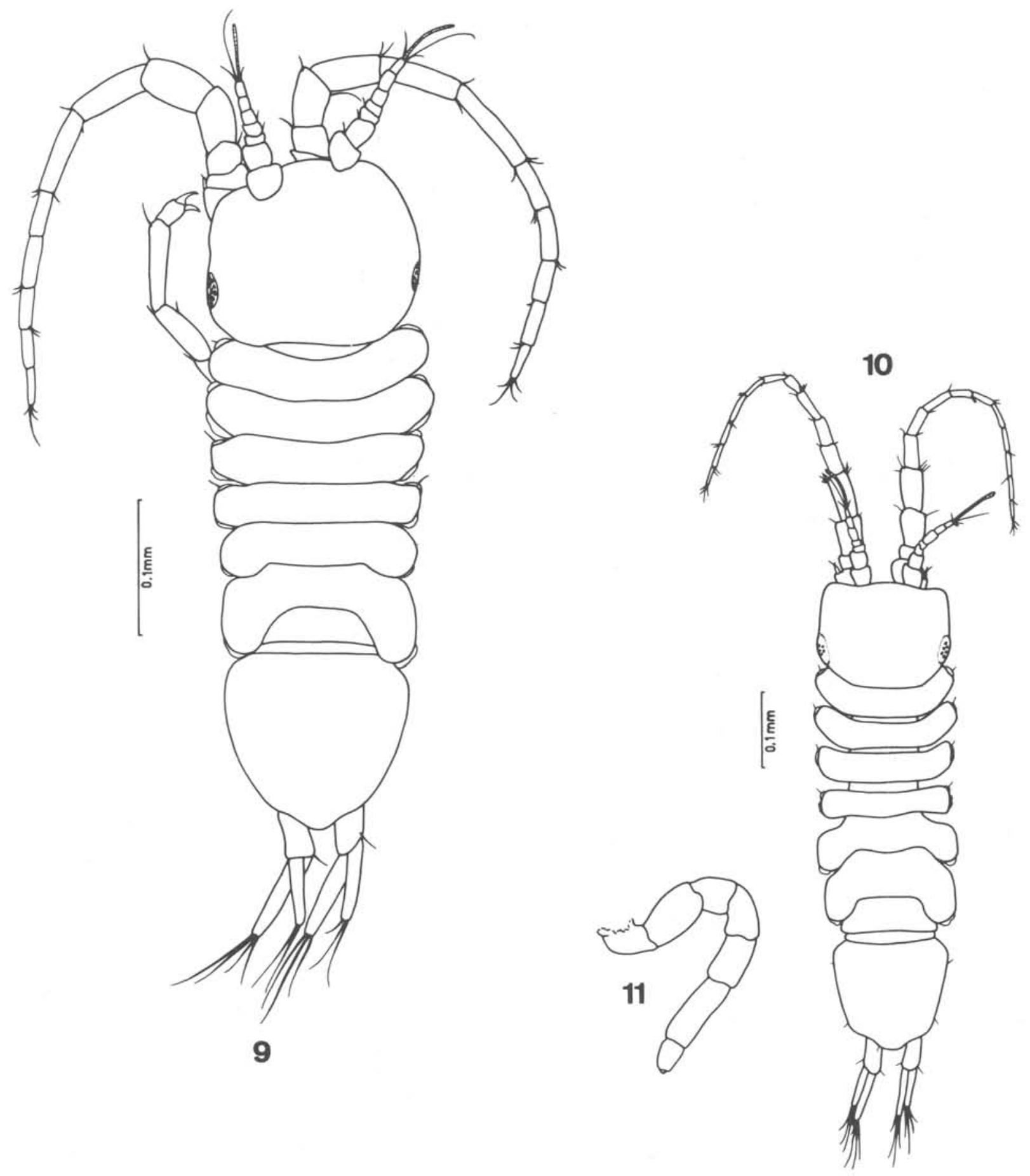

Fig. 9 - Estädio marsupial D e pös-marsupial 1.

Fig. 10 - Jovem no estädio pös-marsupial 2.

Fig. 11 - Pereōpodo VII. Estādio pōs-marsupial 3.

Fig. 11 na mesma escala da Fig. 9. 

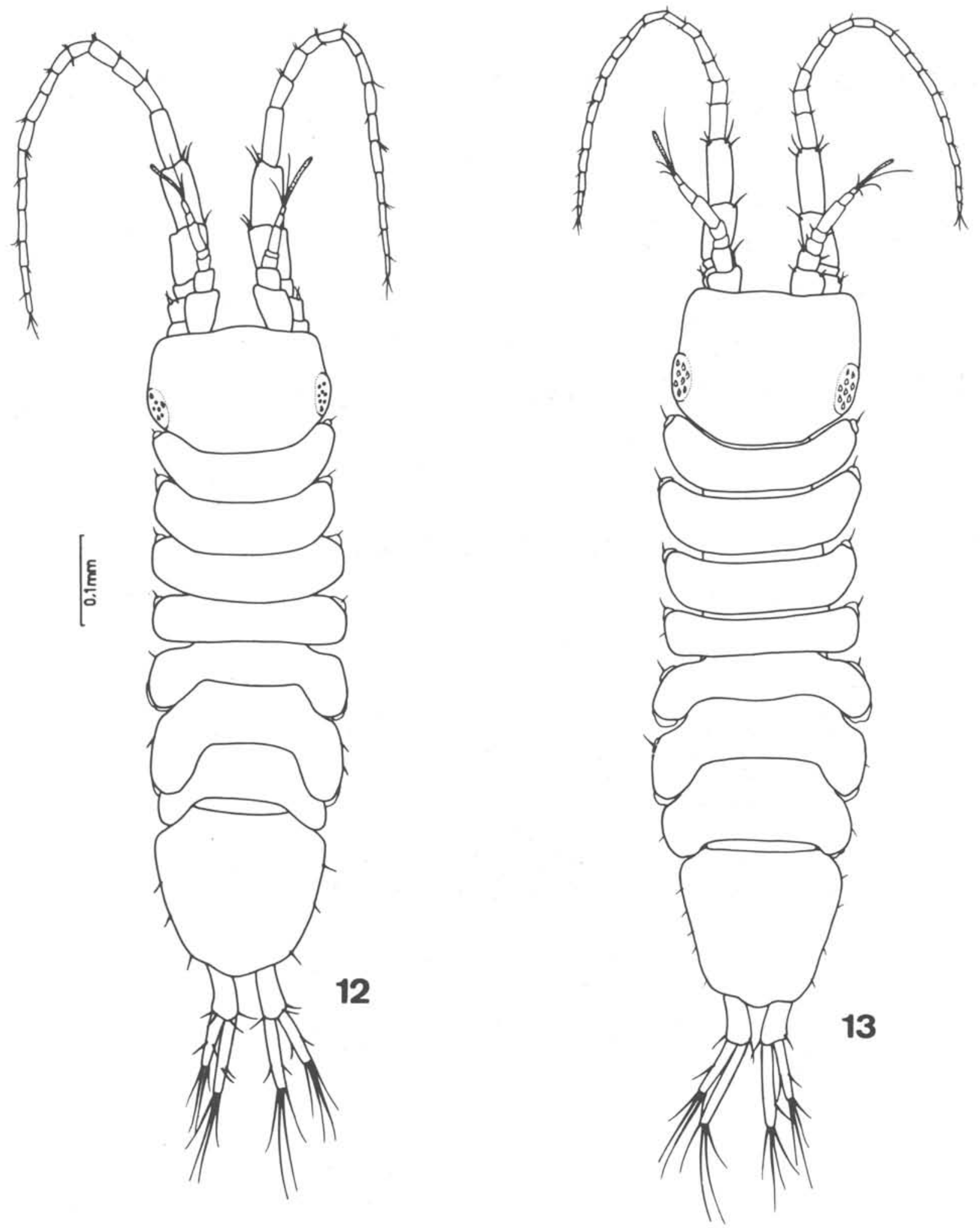

Fig. 12 - Jovem no estädio pös-marsupial 3.

Fig. 13 - Jovem no estädio pös-marsupial 4. 


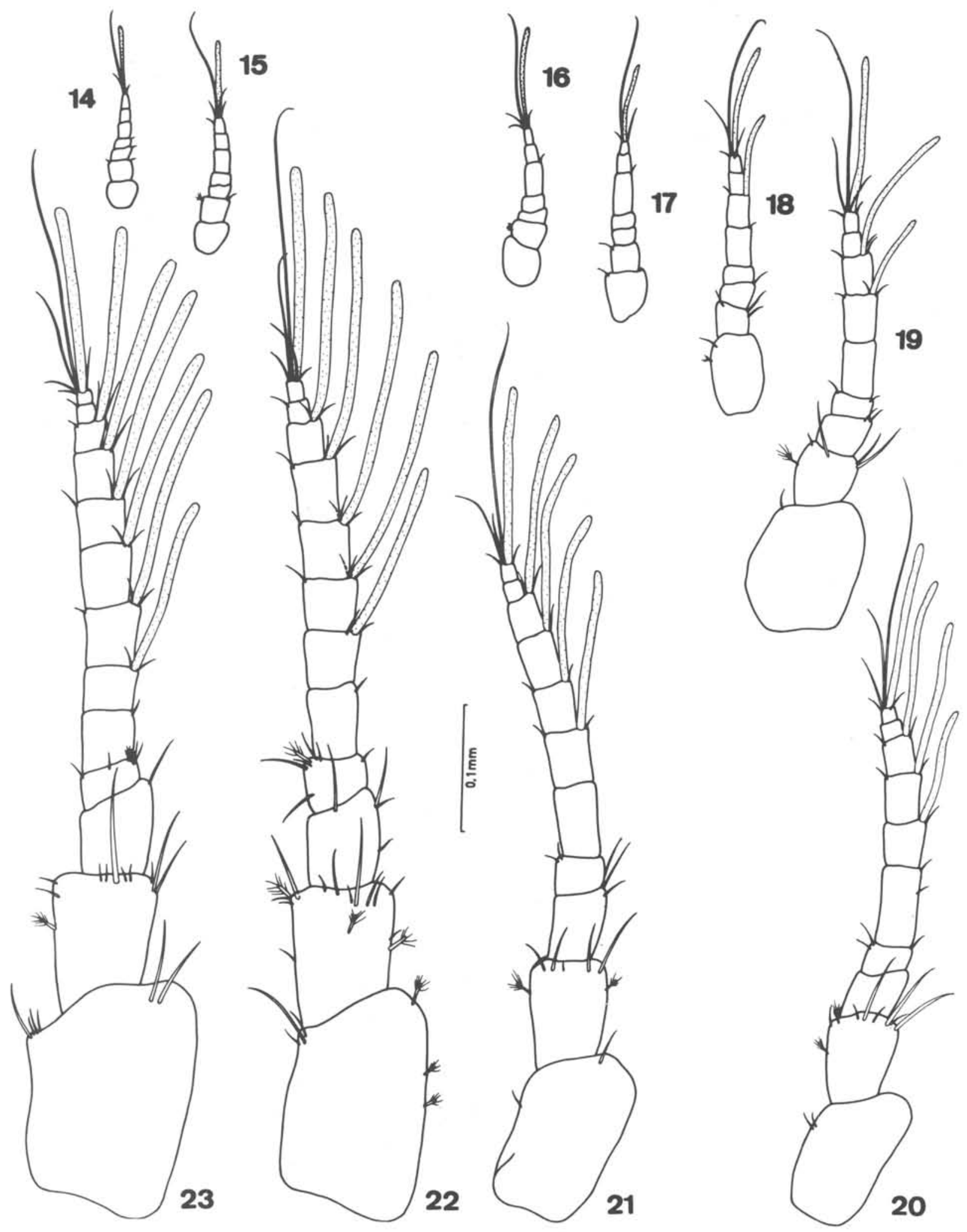

Figs 14-23 - Antena 1 esquerda nos estädios pös-marsupiais 1-10, em machos. 


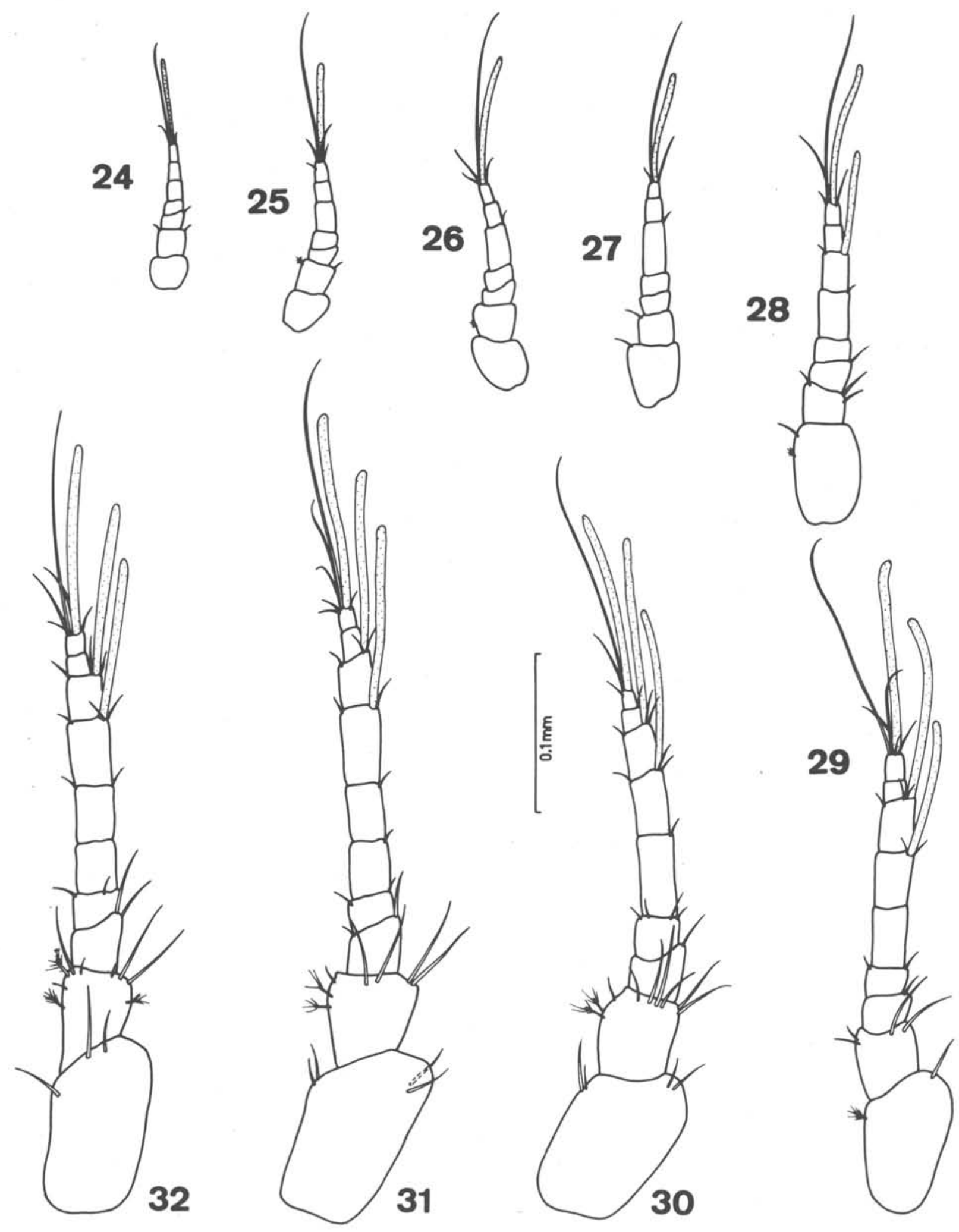

Figs 24-32 - Antena 1 esquerda nos estädios pös-marsupiais 1-9, em fêmeas. 


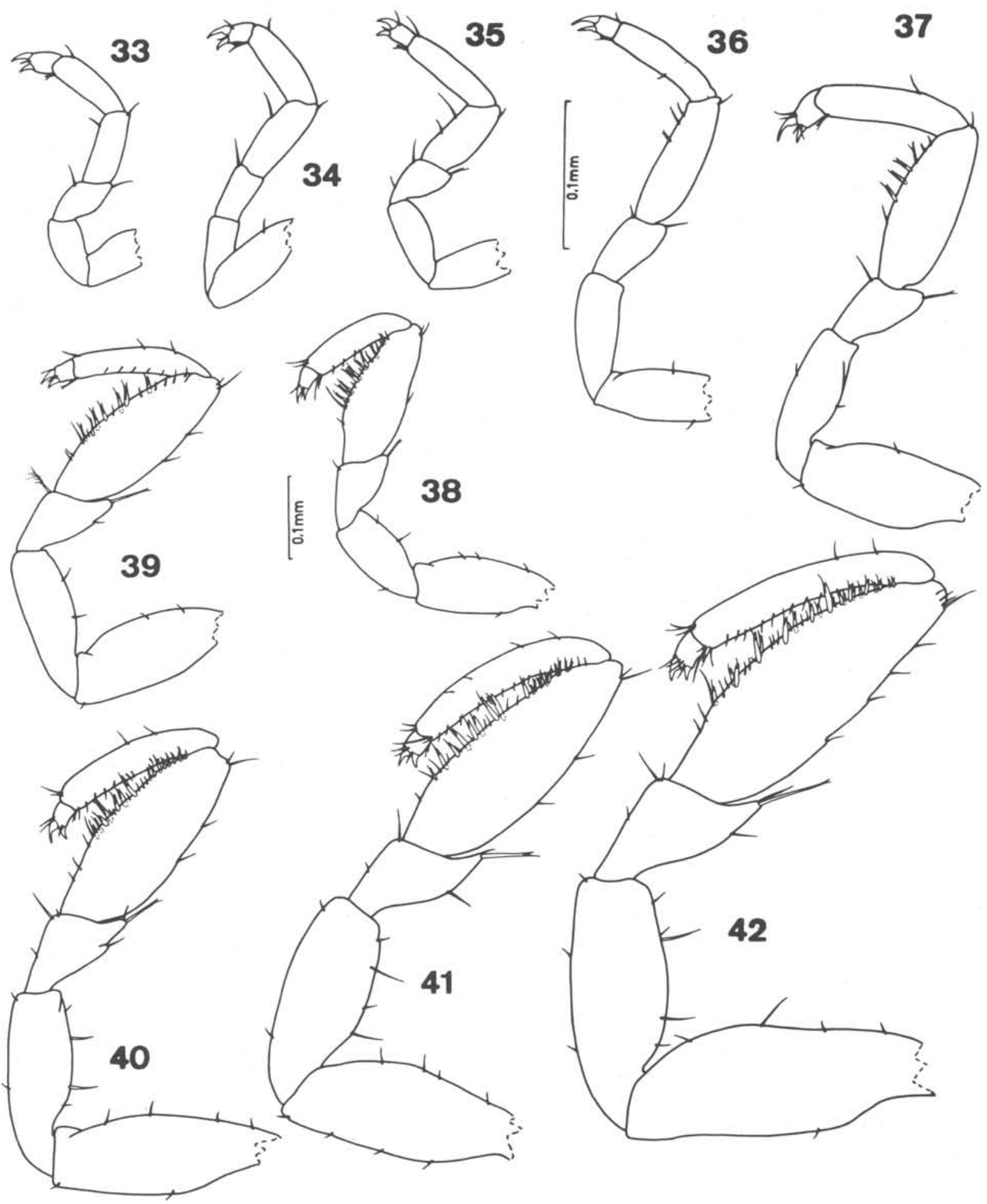

Figs 33-42 - Pereōpodo l esquerdo nos estädios pös-marsupiais 1-10, em machos. Figs 33-37 na mesma escala da Fig. 36 .

Figs 38-42 na mesma escala da Fig. 38 . 

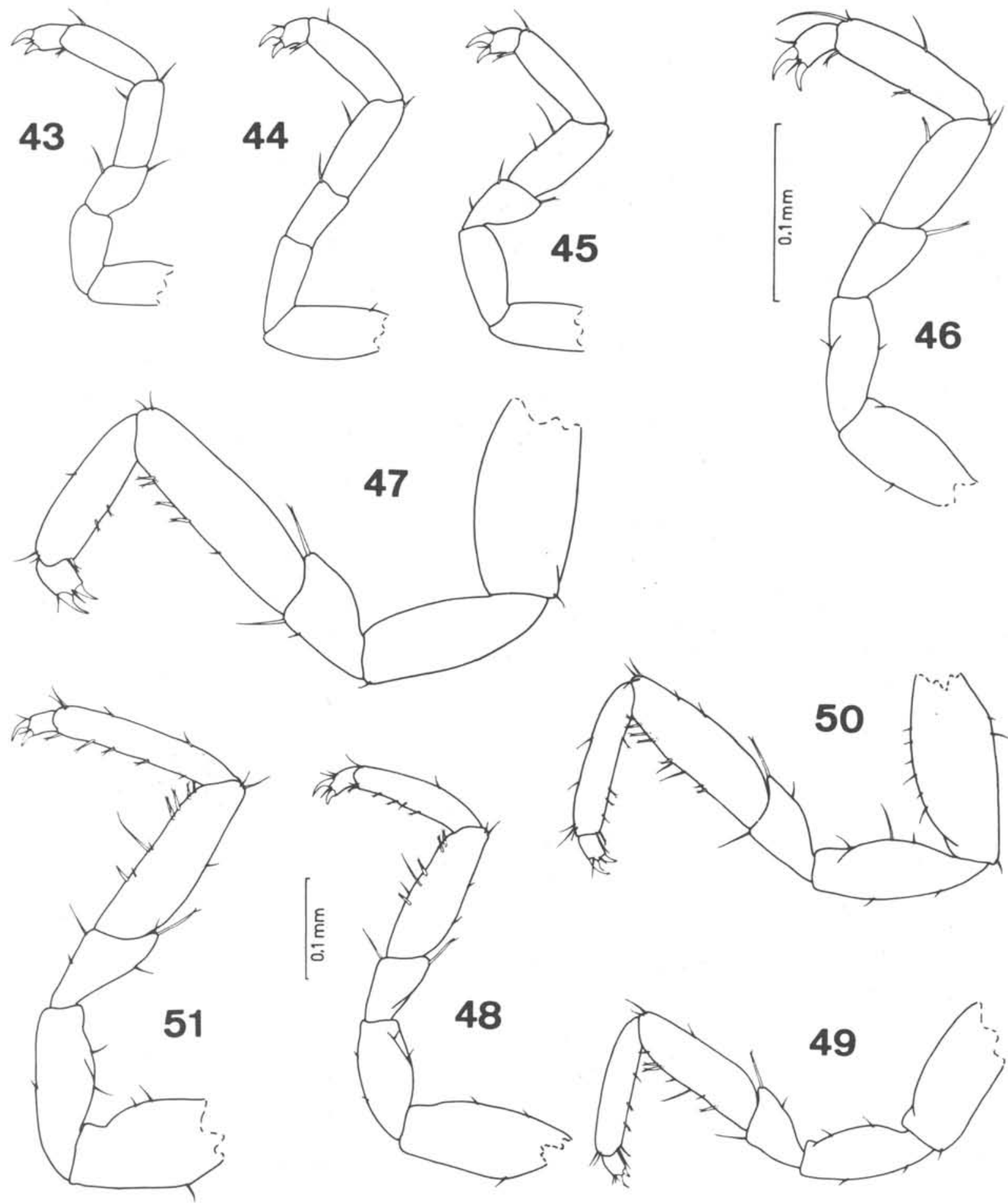

Figs 43-51 - Pereōpodo I esquerdo nos estädios pös-marsupiais 1-9, em fêmeas. Figs 43-47 na mesma escala da Fig. 46.

Figs 48-51 na mesma escala da Fig. 48. 


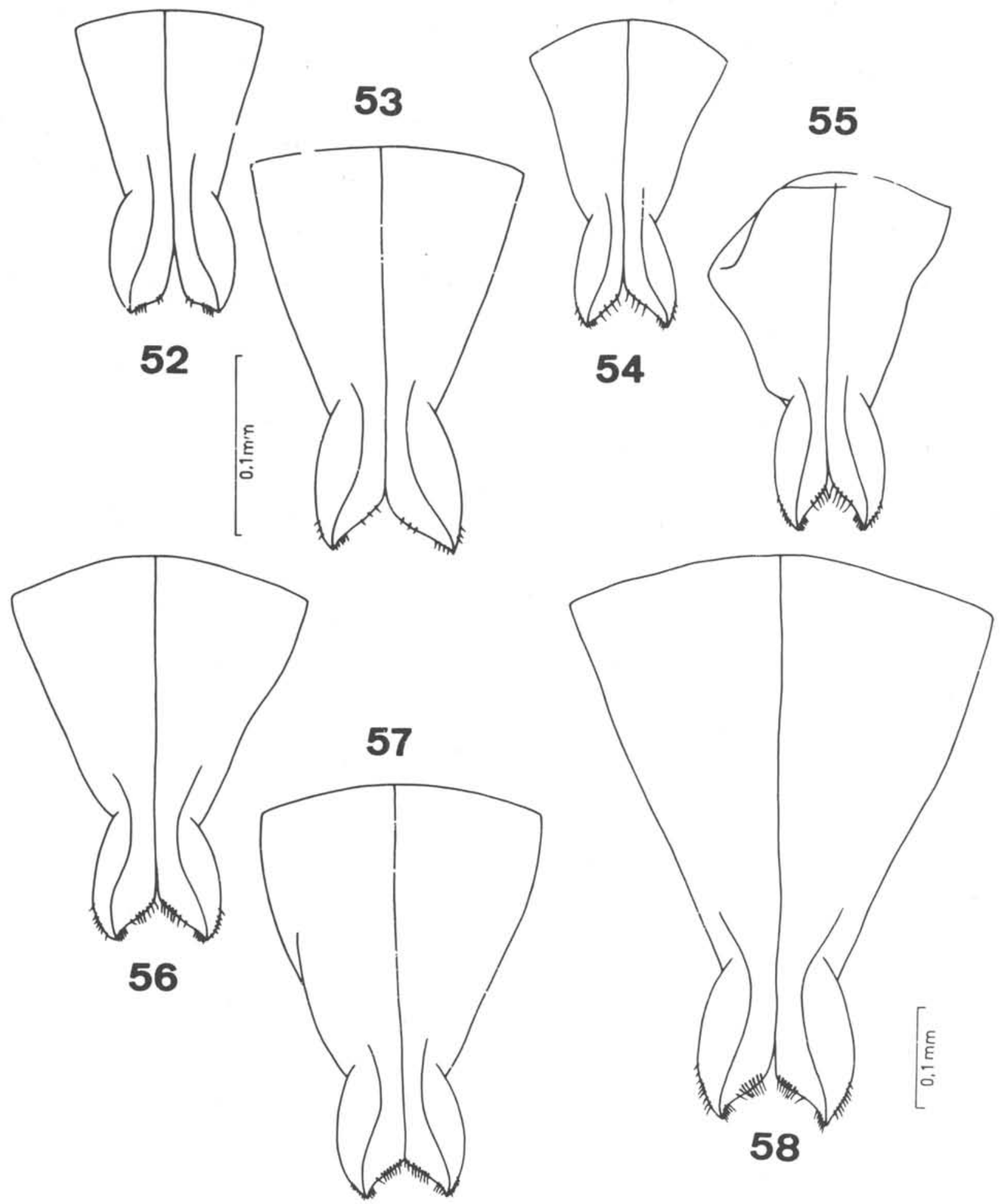

Figs 52-58 - Pleōpodo I masculino nos estädios pös-marsupiais 4-10. Figs 52-53 na mesma escala.

Figs 54-58 na mesma escala da Fig. 58. 


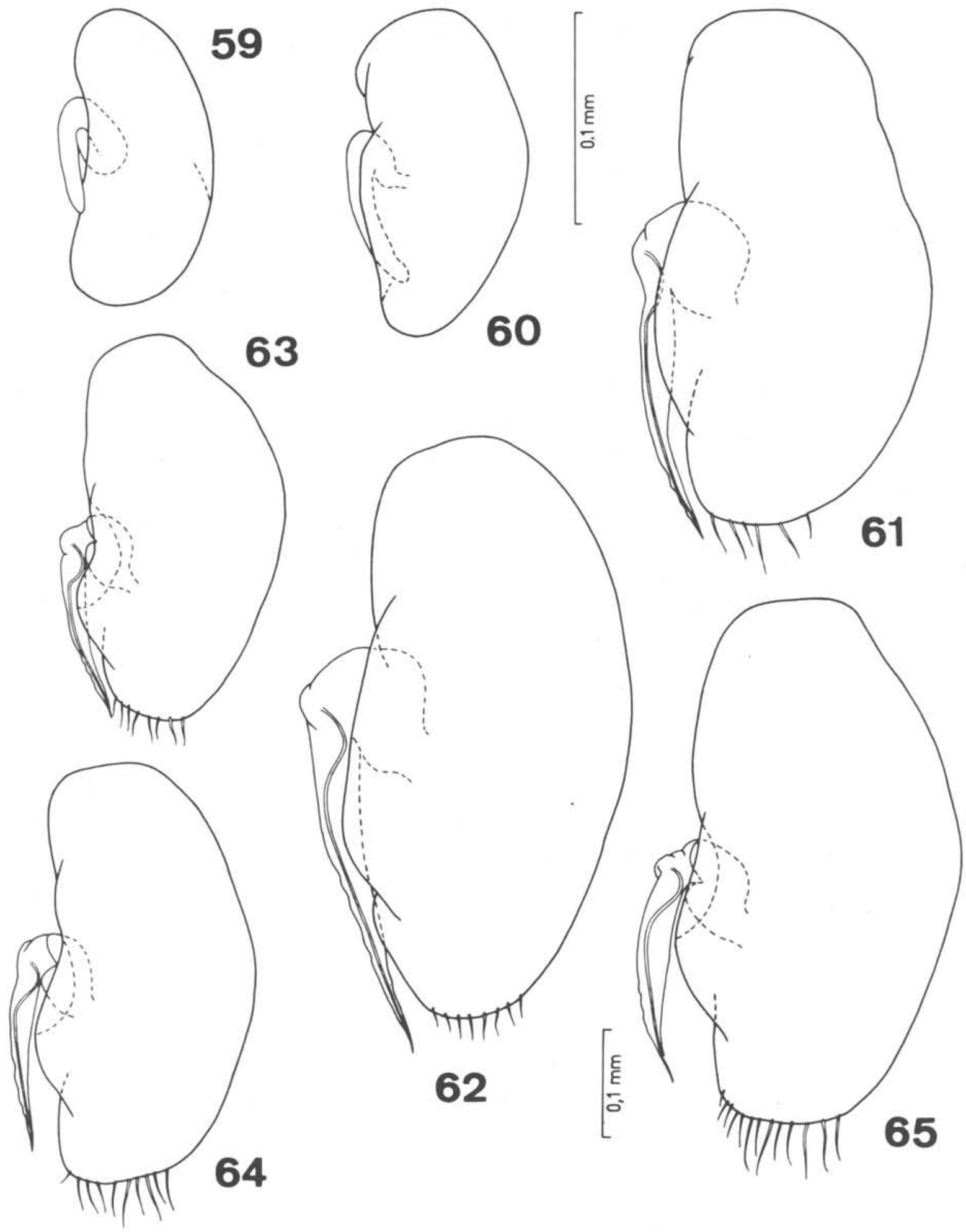

Figs 59-65 - Pleöpodo 2 masculino nos estädios pös-marsupiais 4-10. Figs 59-62 na mesma escala da Fig. 60 .

Figs 63-65 na mesma escala da Fig. 65 . 